\title{
POGLI SisRot LIX: RESULTADOS DE APLICAÇÃO NO PLANEJAMENTO E EXECUÇÃO DE SETORES E ROTAS DE RESÍDUOS SÓLIDOS NO BRASIL
}

\author{
${ }^{1}$ Marcos José Negreiros Gomes \\ Universidade Estadual do Ceará \\ Programa de Pós-Graduação em Administração (PPGA) \\ Av Paranjana, 1740 - Campus do Itaperi - CEP: 60.714-903 \\ Fortaleza - CE - BRAZIL \\ ${ }^{1}$ marcos.negreiros@uece.br \\ ${ }^{2}$ Augusto Wagner de Castro Palhano, ${ }^{3}$ Eduardo César Rodrigues Reis \\ GRAPHVS Consultoria Ltda \\ R. Vicente Linhares, 521 sala 913 - Aldeota - CEP: 60135-270 \\ Fortaleza - CE - BRASIL \\ 2ªugusto@graphvs.com.br; ${ }^{3}$ eduasp@gmail.com
}

\section{RESUMO}

Este trabalho apresenta uma tecnologia inovadora para a elaboração dos Planos de Coleta Veicular, Varrição e acompanhamento dos demais serviços da Gestão de Resíduos. Utilizando técnicas avançadas de setorização e roteamento de veículos, escala, acompanhamento de frota e pessoal, esta tecnologia permite o acompanhamento e fiscalização dos serviços em tempo real pelos gestores, e apoia na elaboração dos planos de forma rápida e otimizada do ponto de vista do custo com pessoal e equipamento. São apresentados casos reais avaliados em campo na coleta domiciliar e na varrição manual em distintas cidades brasileiras (Franca/SP, Campo Grande/MS, Armação de Búzios/RJ and São Paulo/SP), cujos resultados de economia foram de 14 a $28 \%$ na coleta domiciliar e de $7-27 \%$ na varrição manual frente ao que se praticava pelas empresas do setor.

Palavra-chave: Setorização-Roteirização, SAD, Coleta de Resíduos Sólidos.

\begin{abstract}
We present a new technology to make plans and help manage waste collection activities and human street sweeping. It can also follow up and manage solid waste services, optimizing (by least cost) the applications. By using advanced technics from sector-routing, scheduling, fleet and stuff scheduling by following them using integrated GPS system. We present real cases results evaluated in the field from household refuse collection and human street sweeping in distinct Brazilian cities(Franca/SP, Campo Grande/MS, Armação de Búzios/RJ and São Paulo/SP), the results achieved from 12 to $28 \%$ of savings in household refuse collection and from $7-27 \%$ to human street sweeping over the practice work done by the firms responsible for the service.
\end{abstract}

Keywords: Sector-Routing, DSS, Waste Collection. 


\section{Como Citar:}

Negreiros, Marcos; Palhano, Augusto; Reis, Eduardo. POGLI Sisrot Lix: Resultados de aplicação no planejamento e execução de setores e rotas de resíduos sólidos no Brasil. In: SIMPÓSIO DE PESQUISA OPERACIONAL E LOGÍSTICA DA MARINHA, 19., 2019, Rio de Janeiro, RJ. Anais [...]. Rio de Janeiro: Centro de Análises de Sistemas Navais, 2019.

\section{INTRODUÇÃO}

O maior desafio operacional da gestão dos resíduos encontra-se na elaboração, execução e fiscalização dos Planos de Coleta, Varrição e demais serviços. Estes Planos consistem na divisão geográfica do município em setores de coleta e/ou varrição e posterior determinação do trajeto "rua-a-rua" a ser percorrido pelos veículos coletores e/ou varredores, em diferentes dias e horários na semana, para execução do serviço. O mesmo desafio ocorre na elaboração dos Planos dos demais serviços, como limpeza de bocas de lobo, limpeza de feiras-livres e monumentos, entre outros. Atualmente, os gestores destes serviços realizam este planejamento de forma manual, dividindo e re-dividindo a cidade em regiões de coleta e varrição no método de "tentativa e erro", demorando meses para atingirem uma solução exequível e, mesmo assim, pouco ou nunca conseguem um aproveitamento ótimo. Especificamente quanto aos veículos de coleta, existe o problema da dependência do motorista em relação à região de coleta: hoje, o motorista decora o trajeto, ficando a rota vinculada a ele e, no caso da sua falta (férias, doença, etc) a operação será comprometida. Por outro lado, o município não consegue acompanhar e fiscalizar a execução dos serviços a contento, pois a reunião das informações para a análise pelo poder público é demorada.

Este trabalho indica uma solução para estes problemas: através da tecnologia SAD Sistemas de Apoio a Decisão composta por um framework de softwares que permitem projetar e gerenciar os planos de Coleta domiciliar, Varrição e demais serviços. Estes planos são elaborados em minutos e de forma otimizada, ou seja, com menor custo possível. Os planos elaborados pelo SAD SisRot LIX, desenvolvido pela Graphvs Ltda (Graphvs, 2019), calcula os setores de coleta e de varrição, assim como as rotas rua-a-rua de forma que o serviço seja executado no menor custo possível, desde a saída da garagem, passando pela região de coleta até a descarga no aterro ou estação de transferência, considerando veículos de diferentes capacidades de carga.

Também compõe este framework de sistemas computacionais um aplicativo que permite a qualquer gestor ou fiscal acompanhar, em seu celular e em tempo real, a execução dos serviços e outro aplicativo de navegação que, instalado em um celular ou tablet embarcado no veículo de coleta, indica o trajeto rua-a-rua a ser seguido pelo motorista, permitindo a qualquer motorista a execução da rota de coleta, desvinculando a dependência do motorista à rota. No celular o motorista recebe as rotas (viagens de coleta) do setor que vai trabalhar no dia e o sistema acompanha e índica o que deve ser feito (coleta ou não) rua-a-rua, e os gestores acompanham simultaneamente todos os serviços enquanto estão sendo prestados.

Neste trabalho será demonstrada a utilização desta tecnologia na elaboração de setores e rotas de coleta veicular e varrição em duas regiões da cidade de São Paulo, além do resultado em um município brasileiro, com economia próximas a 30\% nas distâncias totais percorridas pelos veículos (economia de combustível, tempo, desgaste mecânico, pneus etc), além de redução da frota (retirada de veículos de operação) e redução de horas-homem e horas extras.

Esta tecnologia apresentada, bem como a matemática, equações, algoritmos das soluções de otimização e os aplicativos são $100 \%$ nacionais, resultado de mais de 30 anos de trabalho 
de pesquisadores e profissionais altamente dedicados ao problema recolha de RSU no Brasil nas suas diversas frentes.

O problema de resetorização com roteamento foi proposto por [1], sendo considerado a princípio como um problema de roteamento em arcos com capacidade (PRAC), [2]. Trata-se, no entanto de um problema mais geral que pode ser encampado por todos os problemas de roteamento em arcos e em nós com ou sem facilidades intermediárias. Esta é a base dos métodos empregados na plataforma desenvolvida, os quais foram estendidos por [3] como sendo o problema heterogêneo de setorização e roteamento que tanto atende a setorização com roteirização para os casos fechados quanto aos abertos, com resoluções provenientes de algoritmos heurísticos e metaheurísticos do problema do agrupamento capacitado heterogêneo e do problema do carteiro rural misto, [4], [5], [6].

A literatura trata o problema de roteamento aberto em arcos como o problema de se formar um caminho Euleriano aberto em um grafo $\mathrm{G}(\mathrm{V}, \mathrm{E})$ conexo e valorado, de tal modo que seja realizado com o menor custo. A escolha do início e fim do percurso é resultante do problema de decisão. Decorrente deste problema, Usberti et al, [7] propuseram um novo problema denominado problema de roteamento aberto em arcos com demanda. Neste caso, o problema considera que em um grafo conexo $\mathrm{G}(\mathrm{V}, \mathrm{E})$ onde existem elos requeridos e que contêm demanda, deseja-se formar circuitos abertos sobre os elos requeridos cuja soma global das distâncias seja mínima sem que nenhum dos circuitos ultrapasse sua capacidade máxima. Este problema pode ser aplicado em muitos contextos, sendo notoriamente importante na entrega de correspondência, na varrição, no controle de doenças endêmicas, na inspeção de linhas elétricas, na inspeção de trilhos, nas rondas militares e policiais, e muitos outros.

O resultado do uso do elenco de algoritmos indicados em uma plataforma POGLI, transparente ao usuário da complexidade inerente dos processos envolvidos, é o motivo principal do trabalho que aqui se enseja. $\mathrm{Na}$ verdade, mais do que simplesmente um algoritmo ou um conjunto deles em um framework computacional de métodos de otimização, mostra-se aqui que para se atingir os resultados pretendidos é necessário ainda muito trabalho para orquestrá-los. Mas diante das facilidades tecnológicas atuais trata-se de um trabalho especialista bastante compensador.

Este artigo está organizado em introdução, quatro seções e a conclusão. Na segunda seção apresenta-se a arquitetura geral computacional do SAD cujos resultados são aqui estudados. Na seção 3 discutem-se os parâmetros usados no sistema para atender à demanda das diferentes aplicações do sistema. Na seção 4 apresentam-se os resultados da aplicação na coleta domiciliar, nas cidades de Franca/SP, Campo Grande/MS e Armação de Búzios/RJ; assim como, apresentam-se os resultados da varrição manual nos trabalhos realizados em São Paulo, onde foram estudadas propostas logísticas para os RSU da cidade em um Procedimento de Manifestação de Interesse (PMI), que aconteceu de Mar-Out/2018, [8].

\section{A TECNOLOGIA POGLI DE APOIO A DECISÃO}

Com o crescimento da demanda de serviços logísticos são necessários sistemas de informações de Apoio a Decisão (SAD) que se compõem de uma série de outros subsistemas, caracterizando-se pelo modelo de software ERP (Enterprize Resource Processing), [9]. Muito se tem desenvolvido neste sentido para os setores formais das empresas no que tange a administração geral (contas a pagar e a receber, contabilidade, pessoal, marketing, estoques, etc). No entanto iniciativas nos setores de logística de distribuição ainda carecem de ferramentas que apoiem na interoperabilidade sistêmica de vários de seus departamentos, como no atacado, sistemas de distribuição porta-em-porta, sistemas de coleta de lixo, controle de doenças e outros. 
Ao longo dos anos Negreiros et al. [10] desenvolveram sistemas de Planejamento Otimizador e Gestão da Logística Integrada - POGLI, Sistemas para Atacadistas, coleta de lixo hospitalar e comercial (SisRot Full) e Controle de Doenças Transmitidas por Arboviroses (WebDengue), assim como o mais recentemente ampliado SisRot LIX. No modelo POGLI para a coleta de lixo, a arquitetura sistêmica permite planejar de forma otimizada e acompanhar a execução em campo dos planos otimizados de dentro ou de fora de empresas do setor que operam com pessoal, frota e diferentes tipos e destinações dos recursos para a coleta domiciliar, seletiva domiciliar, varrição manual e mecanizada, dentre muitos outros serviços.

O esquema POGLI (Figura 1) apresenta uma arquitetura operacional de um conjunto de sistemas computacionais que se integram através de um webservice permitindo que uma série de serviços de planejamento otimizado e gestão para a coleta de lixo possam ser realizados. Setorização e roteirização de coleta domiciliar, seletiva domiciliar e varrição (manual e mecanizada) podem ser planejadas de forma otimizada usando os tradicionais e mais avançados métodos e processos matemáticos de Pesquisa Operacional, os quais estão compondo a plataforma o sistema SisRot LIX. Nela integram-se os sistemas de rotas pontuais SisRot FULL, acompanhamento de campo das rotas planejadas CherryTrack LIX (módulos Motorista e Gestor), o módulo de atribuição de pessoal a setores, o módulos Escalonador que permite a confecção de escalas de coleta dos veículos e pessoal, enquanto ainda une os módulos SisFrota de acompanhamento os gastos e movimentos da frota, os indicadores de manutenção através dos status de rodízio de pneus/óleo/outros, e outros itens da operação diária dos veículos da frota. Por fim o sistema de acompanhamento da produção TrashControl, que permite visualizar o desempenho das equipes nos setores de coleta, a evolução da produção de lixo por setor, circuito, faturamento da coleta por período e mais detalhes sobre eficiência de coleta.

As informações circulam através de um webservice que está disponível na web 24/7, e atua na recepção dos planos e disponibilização das informações de execução das tarefas de acordo com as liberações e atribuições determinadas pelo sistema de operações das empresas do setor.

Esta solução permite ser incorporada a uma empresa de coleta de lixo após a realização de um rigoroso trabalho de replanejamento de setores e roteiros das diversas coletas (domiciliar, seletiva e varrição), a qual passa a funcionar no ambiente sistêmico operacional da empresa em tempo integral. 


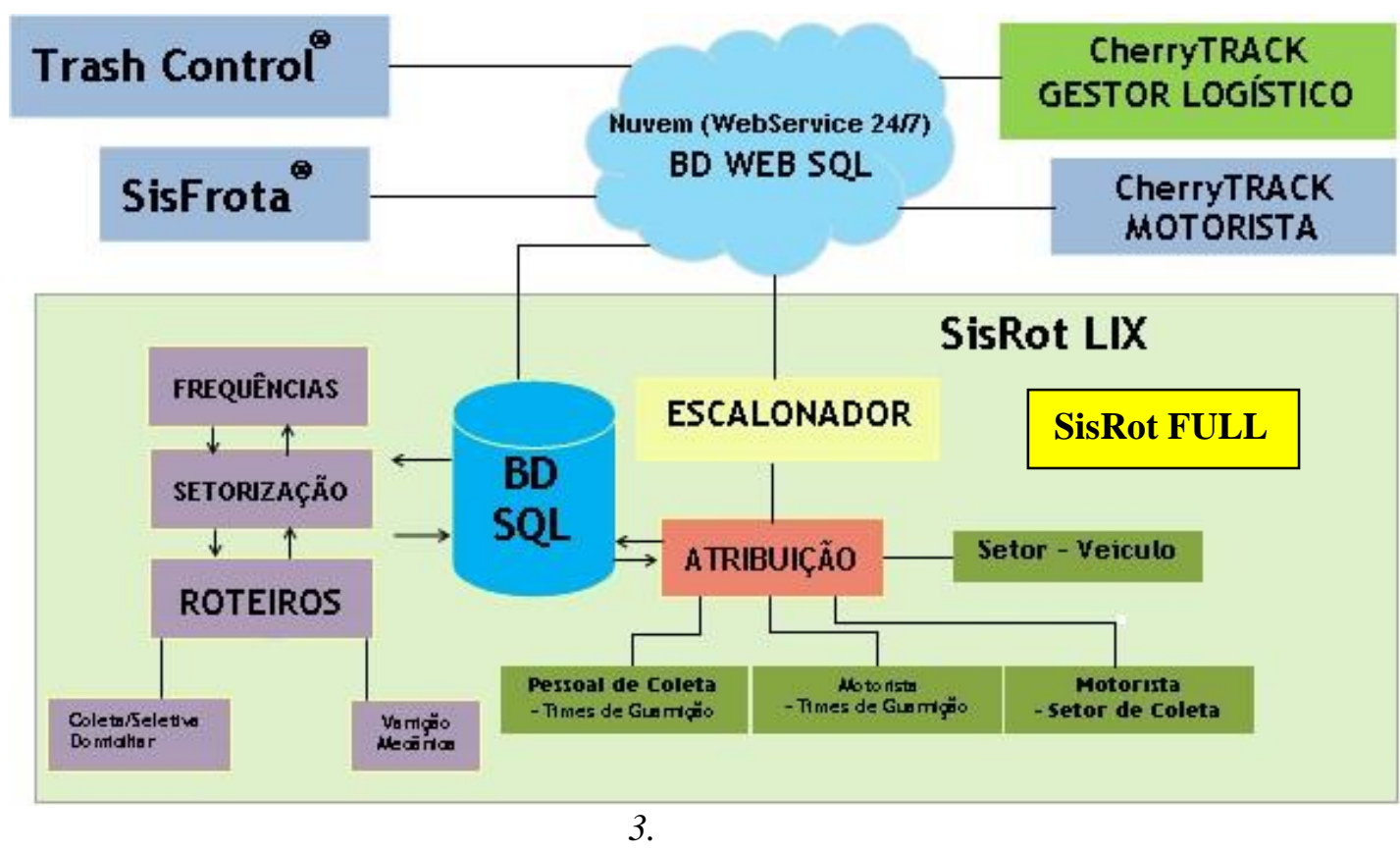

Figura 1 - Arquitetura de um sistema POGLI para a Coleta de Lixo

\section{PARAMETROS DO SISROT LIX PARA OTIMIZAÇÃO}

Para que seja possível o funcionamento da ferramenta é necessário, além do conjunto de métodos de otimização que emprega, um conjunto de parâmetros que governam as condições operacionais de campo. A seguir elencam-se estes parâmetros:

$\checkmark$ Distâncias entre garagem, aterro, transbordo e setor de coleta (Coleta de Varrição);

$\checkmark$ Multiorigens e Multidestinos: otimiza com várias garagens e/ou aterro/transbordos (Coleta de Varrição);

$\checkmark$ Duração da jornada de trabalho da equipe (Coleta Domiciliar, Varrição Manual e Coleta de Varrição);

$\checkmark$ Capacidade de carga dos veículos (os veículos podem ter cargas iguais ou diferentes);

$\checkmark$ Taxa de geração de lixo per capita/região ou por distância percorrida (m);

$\checkmark$ Velocidades do veículo vazio, cheio, coletando ou não coletando;

$\checkmark$ Tempo de descarga da coleta;

$\checkmark$ Coletas por vias mais curtas ou mais rápidas;

$\checkmark$ Identificação das ruas trafegáveis ou não trafegáveis ("puxadas");

$\checkmark$ Mapa censitário (oferta de lixo por densidade populacional ou por domicílio);

$\checkmark$ Pontos especiais de coleta e carga específica.

Algumas características das soluções:

$\checkmark$ Rotas baseadas nas soluções do Problema Generalizado de Roteamento de Veículos para redes genéricas (PGRV);

$\checkmark$ Rotas veiculares são geradas com o mínimo de retornos em "U" e manobras à esquerda ou direita: menor tempo de execução e menor esforço do motorista, assim como mantém o serviço o mais contínuo possível; 
$\checkmark$ É possível a otimização das rotas de coleta seletiva solidária e pontuais (contêineres, ecopontos, sacos da varrição, feiras-livres, monumentos, hospitalar, etc.);

$\checkmark$ Rastreamento/visualização em tempo real dos veículos, lutocares e qualquer equipamento comparando ao que fora planejado;

$\checkmark$ Viagens balanceadas: as rotas são otimizadas para que as cargas entre viagens sejam próximas no setor;

$\checkmark$ Os trajetos entre Garagem-Setor, Setor-Aterro e Aterro-Setor também são otimizados e fazem parte da rota/viagem, junto com a área da coleta. A coleta é otimizada pelo "Caminho Mais Curto" e os trajetos Garagem-Setor, Setor-Aterro e Aterro-Setor podem ser otimizados tanto pelo "Caminho Mais Curto" quanto pelo "Caminho Mais Rápido";

$\checkmark$ A disposição dos sacos de varrição pelo varredor pode ser programada a cada " $\mathrm{x}$ " metros e sempre próxima às esquinas. A rota do veículo que fará a coleta dos sacos da varrição, bem como a rota do veículo utilizado para levar e buscar os varredores para os setores, também são otimizadas para o menor custo usando o roteirizador SisRot FULL;

$\checkmark$ Rastreamento do Lutocar: qualquer rastreador pode ser incorporado ao sistema, permitindo acompanhar a execução do serviço de varrição em tempo real;

$\checkmark$ Visualização das rotas em diversos formatos (Multigrafo, Animado, KML, PDF, XLS e muitos outros).

\section{APRESENTAÇÃO DOS RESULTADOS DE PLANEJAMENTO E ACOMPANHAMENTO DA EXECUÇÃO}

\subsection{Franca/SP}

Neste trabalho foi desenvolvido para a empresa concessionária dos serviços de coleta domiciliar de Franca/SP um conjunto de soluções com base na coleta domiciliar de dois setores bem distantes da garagem (base dos veículos e administração) e do aterro no período de Out-Nov/2017. Foram calculadas soluções de rotas apenas refazendo o percurso de cada viagem, e em seguida foram resetorizados dois setores. A Figura 2 mostra a situação.
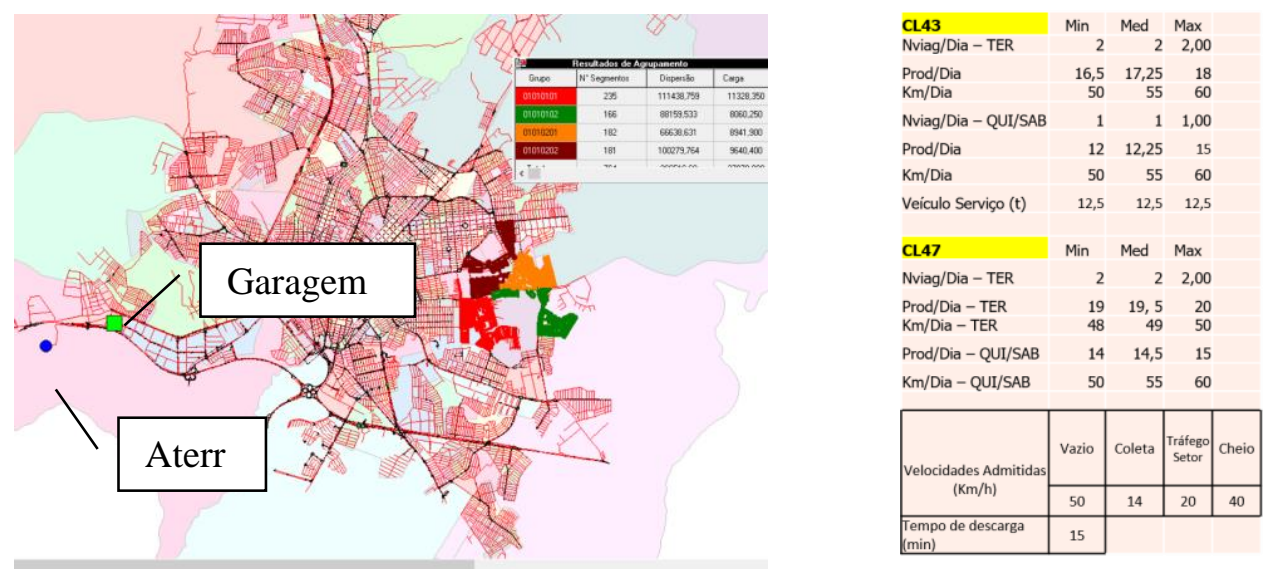

Figura 2 - Situação de revisão de roteiros de coleta para os setores CL43 e CL47 de Franca/SP, imagens produzidas pelo SisRot LIX. 


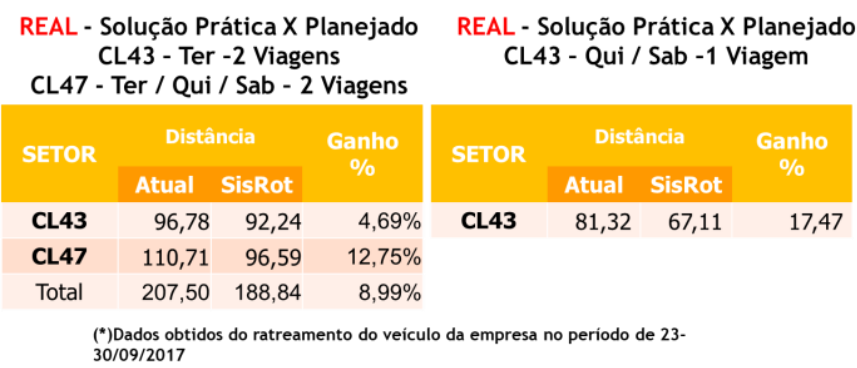

Figura 3 - Resultados de economia de na revisão de rotas para os setores CL43 e CL47 de Franca/SP.

A figura 3 mostra o resultado do novo projeto de rotas, atingindo um total de $9 \%$ no caso de 2 viagens e de $17,5 \%$ quando for uma viagem.

No novo projeto dos setores e geração de novos roteiros, com uma nova configuração geométrica foi elaborada pelo sistema, permitindo ainda maiores economias às obtidas no primeiro caso. Aqui o novo projeto dos setores mostra uma economia global de $15,5 \%$, Figura 4,

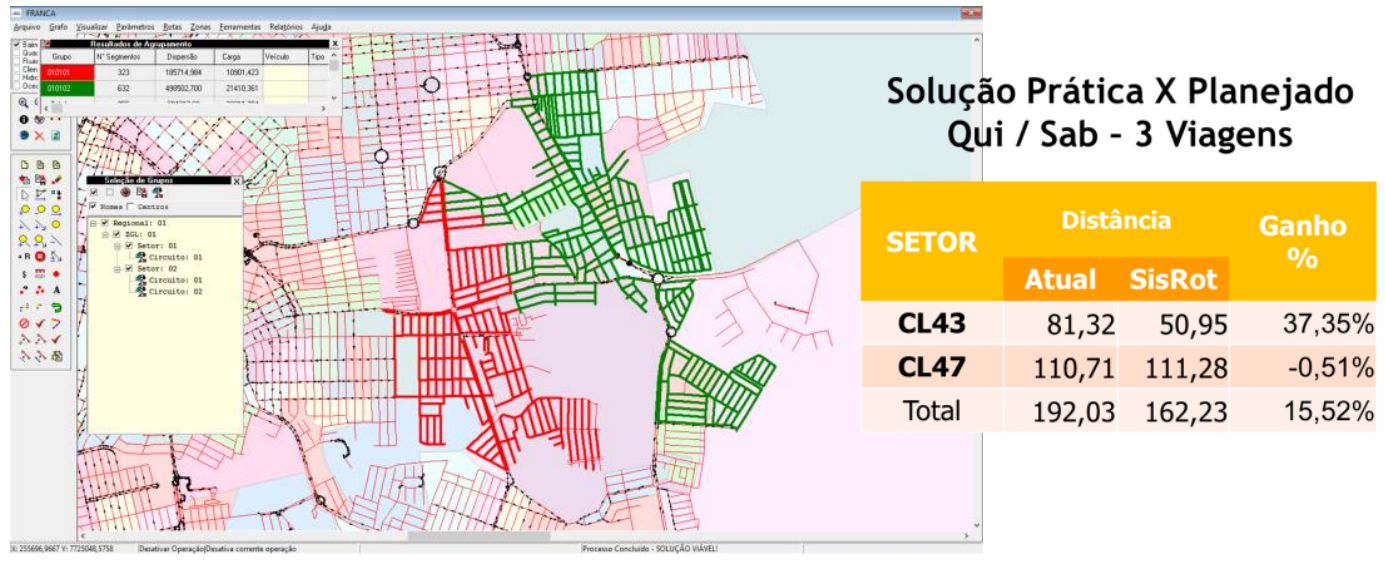

Figura 4 - Resultado da resetorização e novo roteamento de dois setores de coleta em Franca/SP.

\subsection{Município de Campo Grande/MS}

Com população de 885 mil habitantes (IBGE/2018) e 117 setores de coleta, média de 2 circuitos de coleta em cada setor. Foram separados 04 setores para a apresentação dos resultados. Os dados de ABR/2018 (sem otimização) destes setores foram informados pelos gestores da concessionária local, conforme segue:

- Identificação dos setores: setores 12, 19, 21 e 21, Figura 5;

- Coleta através de 01 caminhão "toco" compactador de 9 toneladas, com carga máxima de coleta de $8,5 \mathrm{t}$, para cada setor;

- Frequência de coleta: noturna, alternada 3 x por semana (seg/qua/sex);

- Cada setor precisa de duas viagens (circuitos) por veículo para ser coletado, sendo $1^{\mathrm{a}}$ viagem Garagem-Setor-Aterro e a segunda viagem Aterro-Setor-Aterro;

- Geração de lixo total dos 4 setores: 68t/dia de coleta (média para cada setor de 17 t/dia);

- Distância média diária total percorrida pelos veículos: $478 \mathrm{~km} /$ dia de coleta $(119,5$ $\mathrm{km} /$ veículo-dia); 
- Equipe: nos 4 setores operam 4 motoristas e 12 coletores $(1$ motorista +3 coletores em cada veículo);

- Velocidades: Vazio: 47,0 km/h, Cheio: 38,0 km/h, em Coleta: 6,0 km/h, não coletando $25,0 \mathrm{~km} / \mathrm{h}$;

- Jornada de trabalho total média diária da equipe: 39h43min, média de 9h55min para cada veículo dia.

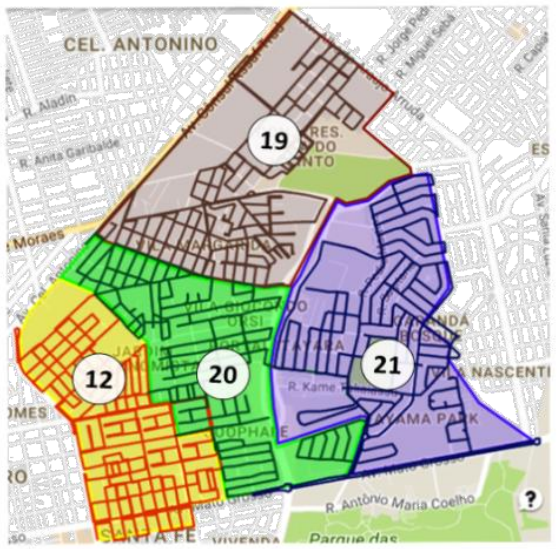

Figura 5 - Geometria atual, com os 04 setores (sem otimização)

\subsubsection{Comparativo entre situação original e os cenários otimizados}

Nos 2 cenários otimizados, percebe-se a redução significativa da distância total percorrida pelos veículos em relação a situação original (Figura 6).

No Cenário 1 a geometria atual dos setores foi mantida e o sistema criou apenas as rotas otimizadas (circuitos) dos veículos, gerando uma economia total nas distâncias percorridas na operação de $\mathbf{1 3 , 7 \%}$.

No Cenário 2, o sistema otimizou tanto os setores quanto os circuitos, considerando a carga do veículo de coleta de 12 toneladas, obtendo uma economia total nas distâncias percorridas na operação de $\mathbf{2 9 , 2 \%}$.

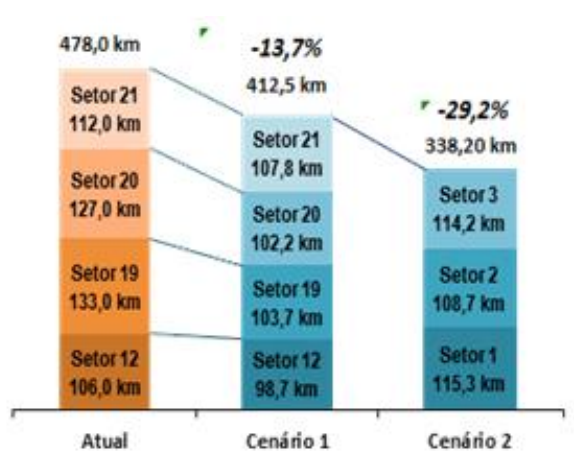

Figura 6 - Escalas de economia entre as duas avaliações.

\subsubsection{Comparativo entre situação original, cenário 2 planejado e cenário 2 executado}

A solução otimizada no Cenário 2 reduziu a quantidade de setores de 04 para 03 setores, os quais foram nomeados Setor 1, Setor 2 e Setor 3 (Figura 7).

A operação otimizada em 3 setores e veículos de 12 toneladas originaram 2 circuitos de coleta por setor, totalizando 6 circuitos (ou viagens ou rotas) de coleta (Figura 12). As avaliações foram acompanhadas com o uso do sistema Cherry Track LIX, cujos setores e rotas foram gerados pelo SisRot LIX e encaminhados automaticamente ao dispositivo de acompanhamento do motorista e do gestor da Graphvs pelo webservice, Figuras 8, 9 e 10. 

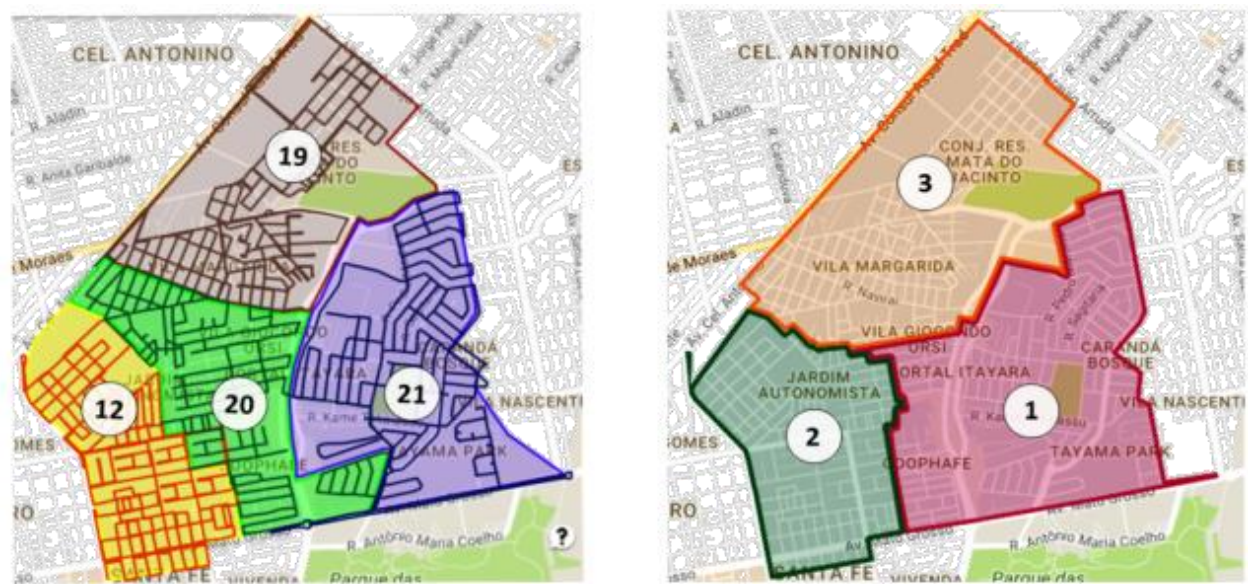

Figura 7 - Mapas indicativos da operação atual, com 04 setores (à esquerda) e o Cenário 2, otimizado para 03 setores (à direita).

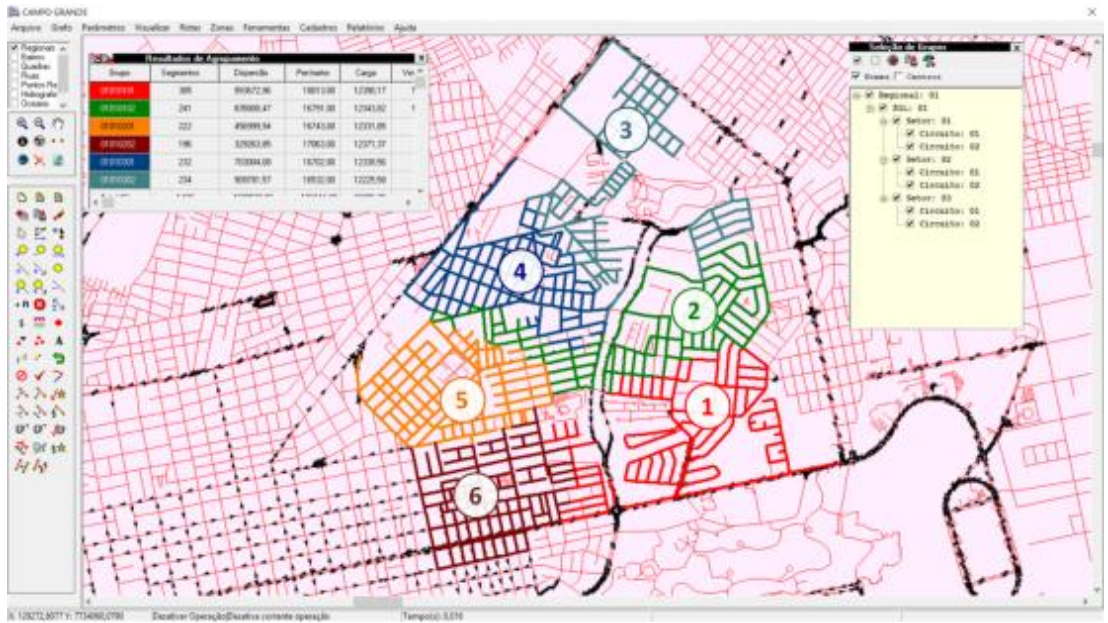

Figura 8 - Tela do SisRot LIX, mostrando os 6 circuitos de coleta (2 circuitos por setor) otimizados.
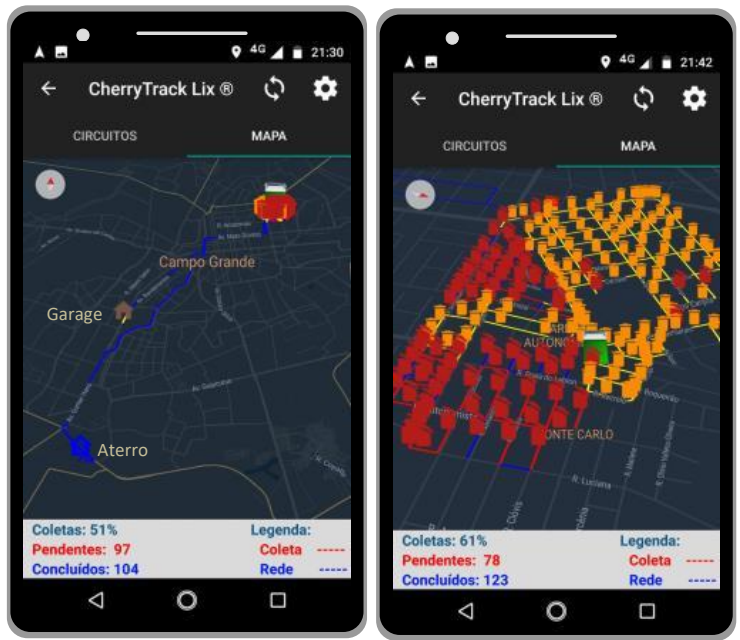

Figura 9 - Telas do CherryTrack LIX de navegação embarcado (visão em modo noturno): à esquerda, visão geral do Circuito 5 (Setor 2), com a indicação da Garagem, Aterro, Setor e os trajetos otimizados a serem seguidos entre eles (em azul). Ao lado, detalhe da operação de coleta, com a indicação das vias coletadas (amarelo), a coletar (vermelho) e a posição do veículo de coleta. A legenda no rodapé mostra ao motorista o andamento da operação de coleta, em quantidade de trechos de vias coletadas (Concluídos), não coletados (Pendentes) e em \% (Coletas). 
Figura 10 - Tela do Aplicativo

CherryTrack LIX Gestor, indicando o acompanhamento da operação no Circuito 1 (Setor 1) e detalhe da tela de seleção dos motoristas/circuitos a serem visualizados.

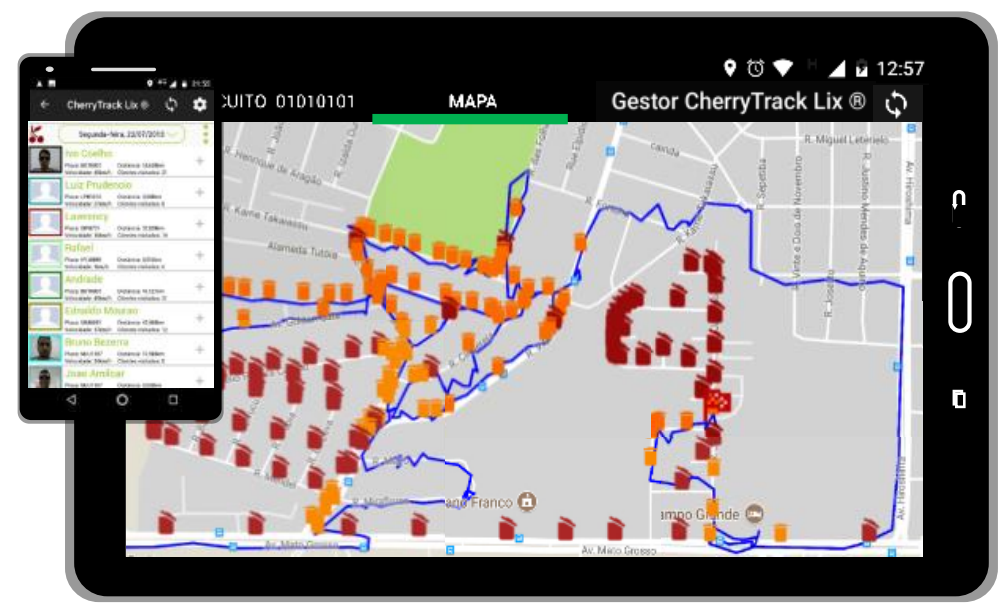

Para melhorar a comparação entre os Cenários Original e Executado, a coleta dos dados foi ampliada: Os dados originais foram obtidos na operação normal, em 04 setores (04 veículos) na semana de 23 a 28/03/18 (segunda, quarta e sexta). Os dados executados foram obtidos da operação nos 03 setores otimizados (03 veículos) na semana de 23 a 27/04/18 (segunda, quarta e sexta).

Os cálculos das jornadas de trabalho, as horas extras foram ajustadas em horas normais, na razão de 1 hora extra $=1,5$ hora normal.

As economias em distâncias de 28,6\% na segunda e 28,5\% na sexta-feira praticamente se igualam à economia projetada de 29,2\% pelo SisRot LIX (Figura 6 Cenário 2). O mesmo não ocorre na quarta-feira, 20/04.

Nesta operação da quarta-feira, 20/04, o relatório detalhado da execução dos circuitos foi analisado, constatando-se que o veículo não executou a operação conforme planejado, desviando-se das rotas indicadas pela otimização. Em função disso, este dado teve que ser desconsiderado, mesmo com a economia de $20,9 \%$.

A economia alcançada em horas-homem motorista, superiores a $20 \%$, deve-se principalmente à "retirada" de uma jornada de trabalho de 01 motorista, resultado da retirada de um veículo da operação. A economia em horas-homem coletor embora presente, foi discreta, pois não houve redução do número de coletores entre a operação atual em 4 setores ( 3 coletores por veículo de $9 \mathrm{t}$ ) e a otimizada em 3 setores (4 coletores por veículo de 12,5 t). O que é o correto a se fazer nestes casos de redução, pois haverá um peso maior por veículo e maior desgaste dos garis nos trajetos individuais.

Importante também relatar que durante os testes com o sistema de acompanhamento Cherry Track Lix, pode-se identificar a todo momento o andamento da coleta, assim como os logradouros ainda a serem percorridos, causando um impacto positivo no motorista e garis que frequentemente queriam saber do "quanto faltava para concluir o trabalho". Além disto, várias tomadas de decisão foram facilitadas (pontos já percorridos, percursos ainda não realizados e outras). 
A figura 11 apresenta o impacto no tempo de coleta e total das áreas analisadas. Observa-se que o ganho foi muito pequeno em relação ao ganho em distância, no entanto deve-se ater que o resultado deste trabalho com a redução de um veículo, 3 veículos fazendo todo o serviço de 4, pouco sobraria no requisito de tempo. No entanto, existe ainda a expectativa de redução neste item, pois o trabalho de campo foi feito em poucos dias, não permitindo aos motoristas e tripulação fixarem as rotas.

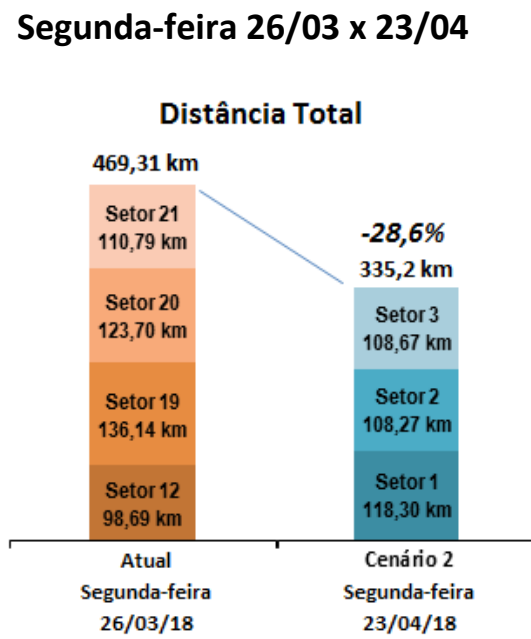

Homens-Hora Motorista Total

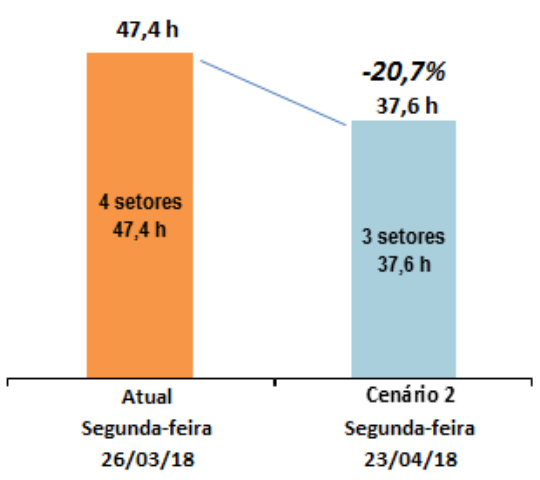

Homens-Hora Coletor Total

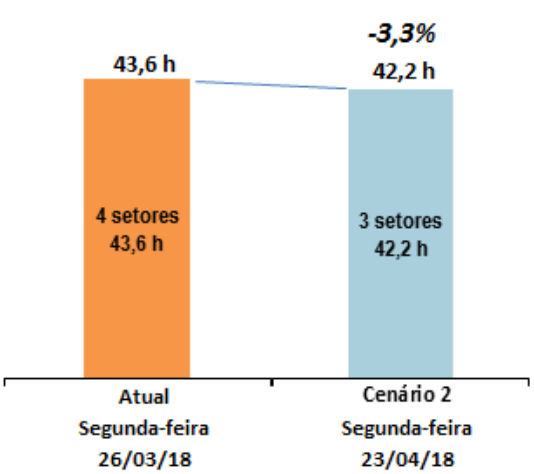

Quarta-feira 28/03 x 25/04

Distância Total

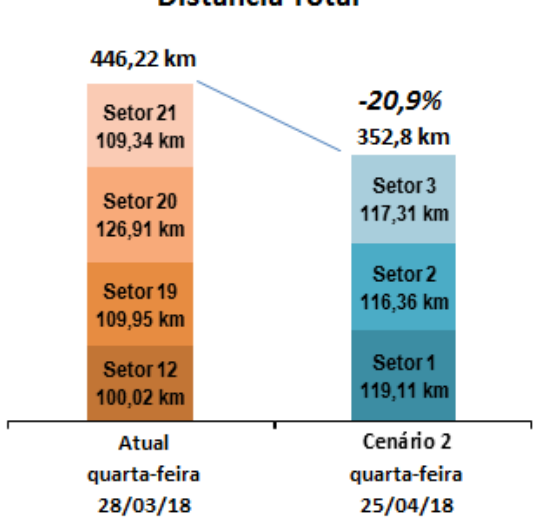

Homens-Hora Motorista Total

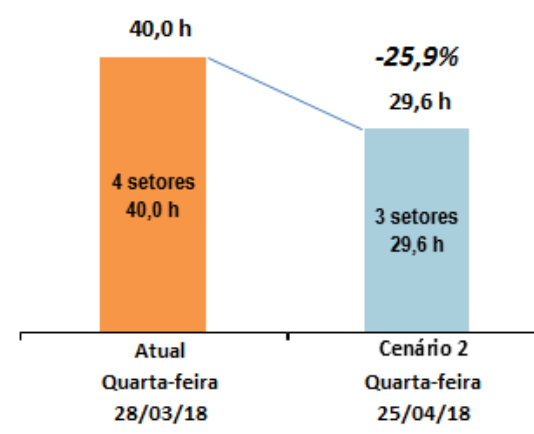

Homens-Hora Coletor Total

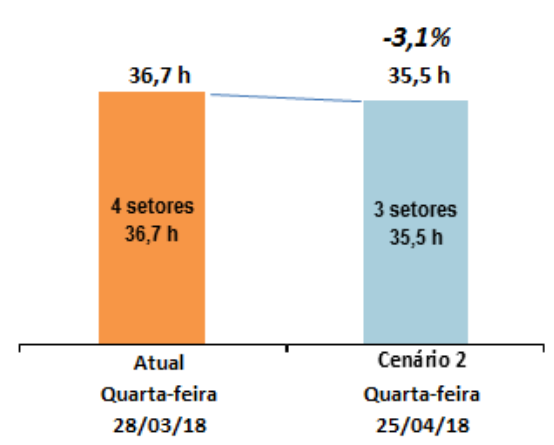

Sexta-feira 23/03 x 27/04

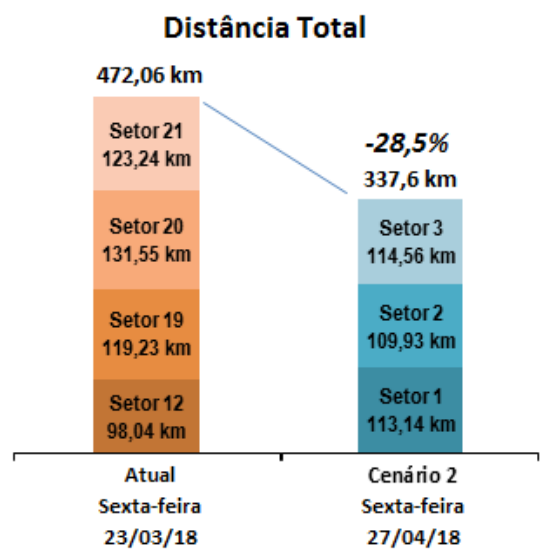

Homens-Hora Motorista Total

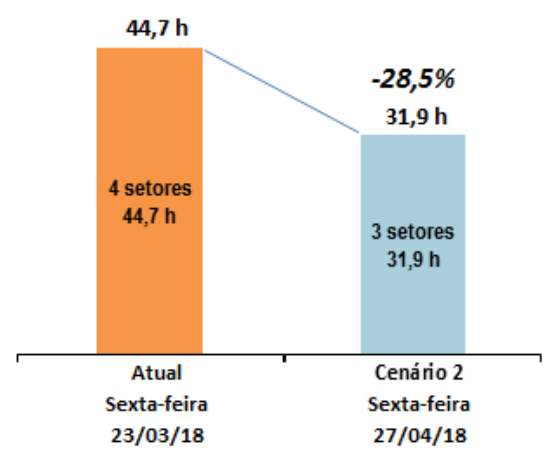

Homens-Hora Coletor Total

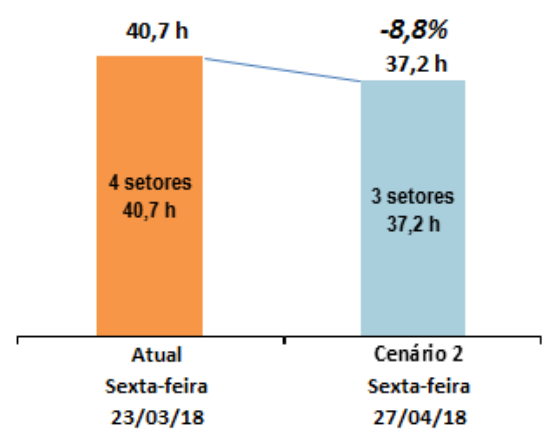

Figura 11 - Comparação das distâncias e duração da operação entre as operações originais atuais (04 setores/04 veículos) de 23 a 28/03/18 e a operação otimizada (03 setores/03 veículos) de 23 a 27/04/18. 


\subsection{Armação de Búzios/MS}

As condições operacionais de Armação de Búzios/RJ são extremas pois a garagem e o aterro encontram-se no município vizinho de São Pedro da Aldeia/RJ, com cenário de posicionamento geográfico de garagem, aterro e setores próximo ao de Franca/SP. Esta região possui alto índice de reclamação da população quanto aos custos da coleta pago pelo município, que se defende em virtude das dificuldades de realizá-la. Os dados operacionais de Armação de Búzios são os que seguem:

- População estimada: 28 mil habitantes - Censo IBGE/2010-2018, na fase normal (MAR-NOV);

- População Flutuante: até $50 \%$ de acréscimo sobre a fase normal (alta-estação: DEZFEV)

- Geração de RSU: Conforme indicado pela empresa concessionária;

- Frota: 6 x 15m³ (Compactação 3x1) aproximadamente 9t de carga máxima;

- Frequência de Coleta: os setores de coleta foram criados para atender às frequências das regiões da cidade definidas pela concessionária sendo todos diários (segunda a domingo), a menos o setor que cobre o bairro RASA onde uma parte é percorrida de forma alternada, em turnos de trabalho das 08:00 às 17:00 com 1:00h de descanso (08h00 úteis);

- Forma de Operação de Coleta: Base na produção. Ou seja, quando termina a execução da coleta no circuito os coletores podem ir para casa; Produção com pouca mobilidade (variação de carga $<3,5 \%$ ) na semana em cada setor; indicadores de produção conforme planilhas fornecidas pela concessionária;

- Logradouros atendidos são aqueles desde São Pedro da Aldeia, passando por Cabo Frio e entrando em Armação de Búzios, onde:

○ Área de Coleta: delimitada pelos mapas entregues pela empresa;

- Segmentos de Logradouros Requeridos: São os segmentos identificados por cores no mapa de setores de Armação de Búzios;

- Base de Operações e Aterro: O veículo deverá partir e terminar a viagem de coleta na Base de Operações localizada em São Pedro da Aldeia e realizar a descarga no aterro Dois Arcos no mesmo município;

- São seis setores: Cem Braças, Rasa, Manguinhos, Geriba, Centro e Ferradura. O circuito RASA é percorrido de segunda a sábado, enquanto os demais de segunda a domingo;

- Os setores são executados com demanda máxima de 8,9t em apenas um setor;

- O serviço é realizado em uma única viagem de Mar-Nov (Baixa estação), e mais de uma de Dez-Fev (Alta Estação).

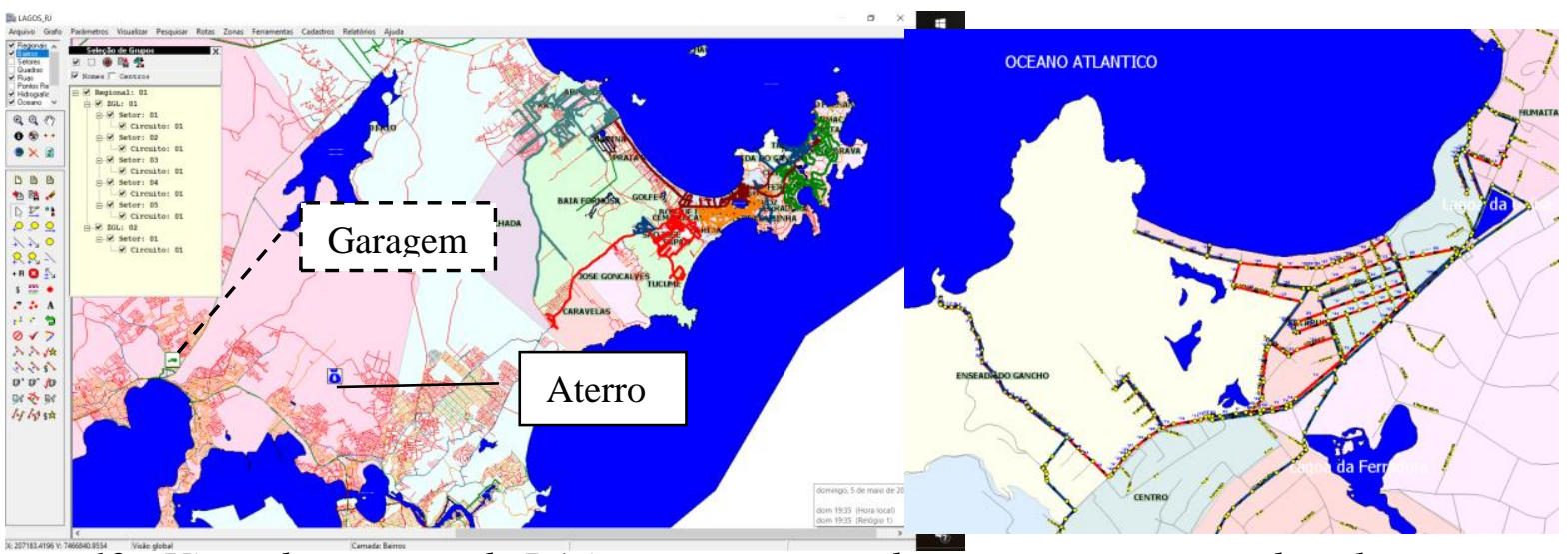

Figura 12 - Visão do contexto de Búzios para geração de setores e percursos da coleta domiciliar. 
As Tabelas 1 e 2 apresentam os resultados de revisão de rotas da coleta domiciliar de Armação de Búzios/RJ para a situação de baixa estação de Mar-Nov. Atingiu-se o resultado de $12,31 \%$ de economia sobre as rotas atualmente praticadas, Tabela 1. Já na tabela 2, é possível ver que a resetorização com nova roteirização dos 6 setores permite uma economia um pouco maior que pode atingir $12,77 \%$. Vê-se também a prevalência no tempo de trabalho dos percursos da garagem a Búzios e para o aterro, dominando e justificando o resultado ainda pequeno na economia proveniente da resetorização.

Tabela 1: Resultados de roteirização comparado ao que se pratica na cidade pela empresa concessionária, considerando a revisão da distância de deslocamento.

\begin{tabular}{|c|c|c|c|c|c|c|c|c|c|c|c|c|}
\hline \multicolumn{2}{|c|}{ SELLIX AMBIENTAL } & \multirow[b]{2}{*}{ Nome } & & \multicolumn{3}{|c|}{ CIRCUITOS ATUAIS MANTIDOS } & \multicolumn{4}{|c|}{ Armação de Búzios } & \multirow[b]{2}{*}{ Produtivo } & \\
\hline \multirow[t]{4}{*}{ Setor } & Circuito & & & Producao 1 & G->Rota & Rota & ota->Aterr $r$ & rro->Garag & Total & mprodutive & & \\
\hline & \multirow{2}{*}{ sons } & \multirow{2}{*}{ Cem Braças } & Praticado & 8 & 32,9 & 40 & 23,9 & $9^{\prime}$ & 105,8 & $62,19 \%$ & $37,81 \%$ & \\
\hline & & & SisRot Lix & 7,5 & 21,665 & 30,211 & 15,831 & $9^{\prime}$ & 76,707 & $60,62 \%$ & $39,38 \%$ & \\
\hline & & & & & & & & Economia & $-27,50 \%$ & & & \\
\hline \multirow{3}{*}{2} & \multirow{3}{*}{1} & \multirow{3}{*}{ Ferradura } & Praticado & 7,2 & 41 & 36,4 & 24,9 & 9 & 111,3 & $67,30 \%$ & $32,70 \%$ & \\
\hline & & & SisRot Lix & 8 & 33,049 & 42,968 & 21,876 & $9^{\prime}$ & 106,893 & $59,80 \%$ & $40,20 \%$ & \\
\hline & & & & & & & & Economia" & $-3,96 \%$ & & & \\
\hline \multirow{3}{*}{3} & \multirow{3}{*}{1} & \multirow{3}{*}{ Geribá } & Praticado & 7,5 & 41 & 27,8 & 19,9 & 9 & 97,7 & $71,55 \%$ & $28,45 \%$ & \\
\hline & & & SisRot Lix & 6,9 & 28,452 & 27,988 & 22,16 & $9^{\prime}$ & 87,6 & $68,05 \%$ & $31,95 \%$ & \\
\hline & & & & & & & & Economia & $-10,34 \%$ & & & \\
\hline \multirow{3}{*}{4} & \multirow{3}{*}{1} & \multirow{3}{*}{ Manguinhos } & Praticado & 5,6 & 38 & 37,6 & 21,9 & 9 & 106,5 & $64,69 \%$ & $35,31 \%$ & \\
\hline & & & SisRot Lix & 7,7 & 30,193 & 32,869 & 15,781 & $9^{\prime \prime}$ & 87,843 & $62,58 \%$ & $37,42 \%$ & \\
\hline & & & & & & & & Economia & $-17,52 \%$ & & & \\
\hline \multirow{3}{*}{5} & \multirow{3}{*}{1} & \multirow{3}{*}{ Centro } & Praticado & 8,5 & 34 & 31,9 & 21,3 & 9 & 96,2 & $66,84 \%$ & $33,16 \%$ & \\
\hline & & & SisRot Lix & 8,9 & 26,311 & 32,05 & 21,079 & $9^{\prime \prime}$ & 88,44 & $63,76 \%$ & $36,24 \%$ & \\
\hline & & & & & & & & Economia" & $-8,07 \%$ & & & \\
\hline \multirow{3}{*}{6} & \multirow{3}{*}{1} & \multirow{3}{*}{ Rasa } & Praticado & 7,2 & 29,2 & 55,7 & 23,9 & 9 & 117,8 & $52,72 \%$ & $47,28 \%$ & \\
\hline & & & SisRot Lix I & 9,84 & 39,241 & 56,227 & 30,682 & 9 & 135,15 & $58,40 \%$ & $41,60 \%$ & 2 Rotas $(5 t$ \\
\hline & & & & & & & & Economia" & $14,73 \%$ & & & \\
\hline \multirow{4}{*}{6} & & & Praticado & 7,2 & 29,2 & 55,7 & 23,9 & 9 & 117,8 & $52,72 \%$ & $47,28 \%$ & \\
\hline & 1 & Rasa & SisRot Lix 1 & 8,2 & 22,216 & 58,911 & 19,495 & $9^{\prime}$ & 109,622 & $46,26 \%$ & $53,74 \%$ & 1 Rota \\
\hline & & & & & & & & Economia & $-6,94 \%$ & & & \\
\hline & & & & & & & & Total SELL & 635,3 & & & \\
\hline Opção 1 - & sando 2 ro & s em Rasa & & & & & & Total SisRi & 582,633 & & & \\
\hline Opção 2 - & sando 1 ro & em Rasa & & & & & & Economia & $-8,29 \%$ & & & \\
\hline & & & & & & & & Total SELL & 635,3 & & & \\
\hline$(1-*)$ Cons & era $20 \%$ de & umento de carg & ga se os dois & is forem feit & cos no mesn & o dia & & Total SisRi & r 557,105 & & & \\
\hline (ii) Estam & considerar & lo como produç & ão a produç & ção diária m & náxima na s & mana cor & nforme infc & Economia & $-12,31 \%$ & & & \\
\hline (iii) Admit & os os veícu & s serem de $9 \mathrm{t}$ & ou $15 \mathrm{~m} 3$ (3:1 & & & & & & & & & \\
\hline (iv) Os nur & ros em lar & jja FORAM COR & RIGIDOS DA & A PLANILHA & TOMANDO & O PERCU & JRSO MAIS E & ECONÔMICO & O da bande & leira de saída & a do setor a & ao aterro \\
\hline Porém a $\$$ & LIX consid & a a distância er & ntre o Acess & so de Baia Fc & ormosa e o & Aterro (en & $\mathrm{m}$ todos os $\mathrm{c}$ & casos) & & & & \\
\hline Significad & & & & & & & & & & & & \\
\hline G-> Rota & & Garagem inícic & o da rota & & & & & & & & & \\
\hline Rota & & Percurso início & da Rota ao & o Fim da rota & a da coleta & & & & & & & \\
\hline Rota->At & & Percurso fim d & da rota de co & oleta ao ate & & & & & & & & \\
\hline Aterro-> & ragem & Percurso Aterr & ro->Garagem & & & & & & & & & \\
\hline
\end{tabular}

Tabela 2: Resultados de roteirização comparado ao que se pratica na cidade pela empresa concessionária, considerando a revisão da distância de deslocamento.

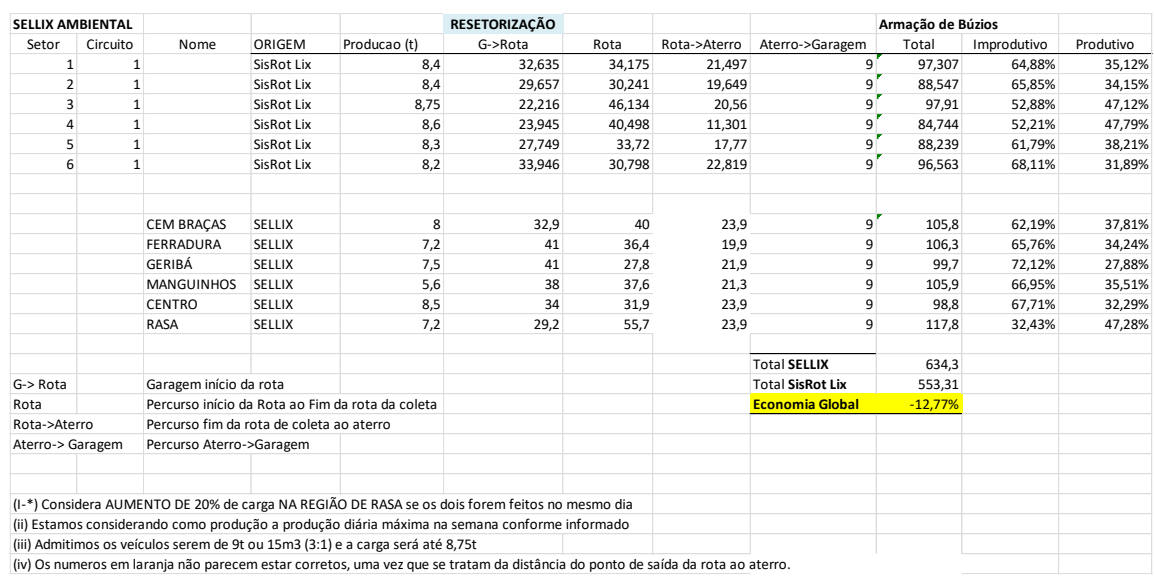




\subsection{Varrição Manual}

A varrição pública é um processo considerado indivisível para a Prefeitura Municipal de São Paulo, local onde foi realizado este estudo. É muito complexa de se organizar, uma vez que o seu planejamento depende claramente do fluxo de pessoas, veículos e arborização nos logradouros públicos. Para atender a esta demanda, as subprefeituras são divididas em regiões com frequências de varrição definidas (ao todo 76 diferentes frequências para a cidade de São Paulo), setores de varrição que compreendem a tarefa de um grupo de varredores em uma região de mesma frequência, e circuitos, que são os locais onde cada equipe de varredores deverá realizar a tarefa de varrição. Tais serviços são fiscalizados em grupos de setores (normalmente 1 fiscal para cada 5 setores, com 3 equipes de garis em cada setor, ou 15 equipes de garis por fiscal). Este serviço é bastante oneroso pois demanda mais de $40 \%$ do custo total com os indivisíveis alcançando o montante de $\mathrm{R} \$ 1,2$ bilhões/ano, [8].

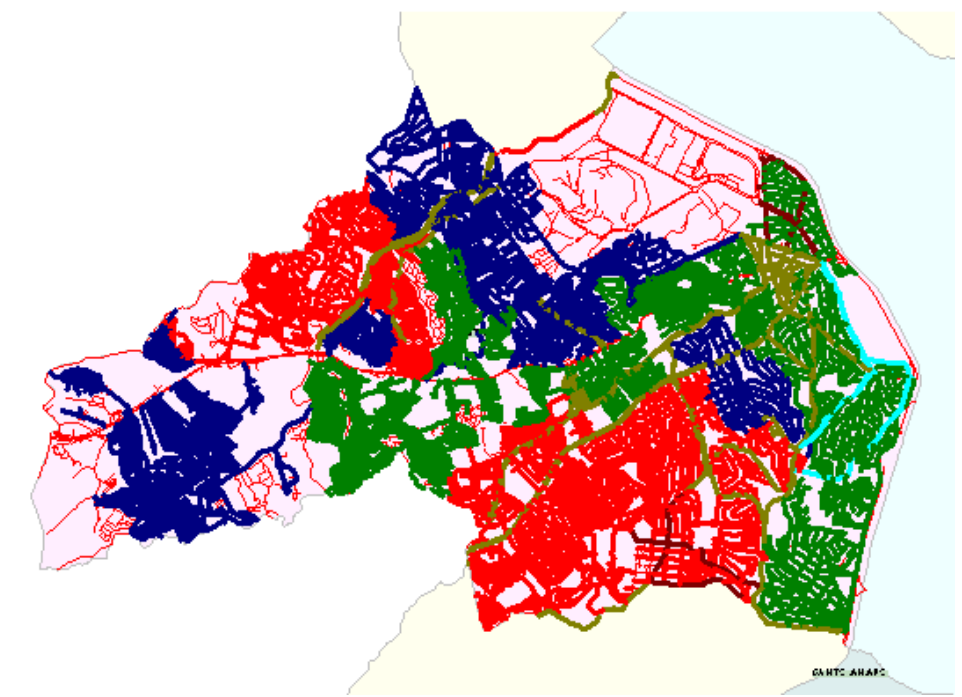

Figura 13 - Mapa de frequências da subprefeitura de Butantã, BT. Entre as cores mais evidentes, tem-se: Azul Marinho: QUA/SAB - M, Verde: SEG/QUI-M, Vermelho: $T E R / S E X-M$.

A varrição é feita em muitas componentes: Manual, Mecanizada, Calçadões, Praças e Instalações Públicas, etc. Este estudo concentrou-se na realização dos planos de varrição manual. Na varrição manual de São Paulo, uma equipe é formada por dois garis trabalhando conjuntamente no mesmo lado de sarjeta, usando um lutocar e seus equipamentos habituais de remoção e indumentária apropriada. Cada equipe percorre em média 1,228 $\mathrm{km} / \mathrm{h}$ de varrição, e anda sem varrer a uma velocidade que varia entre $2,5-3 \mathrm{~km} / \mathrm{h}$. Neste ritmo um percurso de 6-7 $\mathrm{km}$ pode ser feito em um dia de trabalho.

A abordagem considerada para a varrição manual em São Paulo é por eixo de rua, Figura 14. Esta abordagem indica que o percurso será feito pela equipe de varredores contando o perímetro dos logradouros de varrição do setor a distância de meia-jornada do trabalho da equipe (7h20min) em um caminho que parte de um ponto inicial e vai a um ponto final que minimiza o custo do percurso, para em seguida retornar. Na primeira passagem do percurso os varredores fazem um lado das sarjetas enquanto no retorno eles fazem o outro lado das sarjetas (se houver) dos mesmos logradouros que precisam ser varridos.

Na Figura 15, mostra-se o percurso projetado para o varredor de rua designado para cobrir o conjunto de logradouros indicado. Vê-se que a equipe de varredores parte de um ponto inicial e conclui a sua tarefa em um ponto que minimiza o custo global do percurso da 
equipe de varredores, para então retornar ao ponto inicial pelo mesmo percurso no sentido contrário.

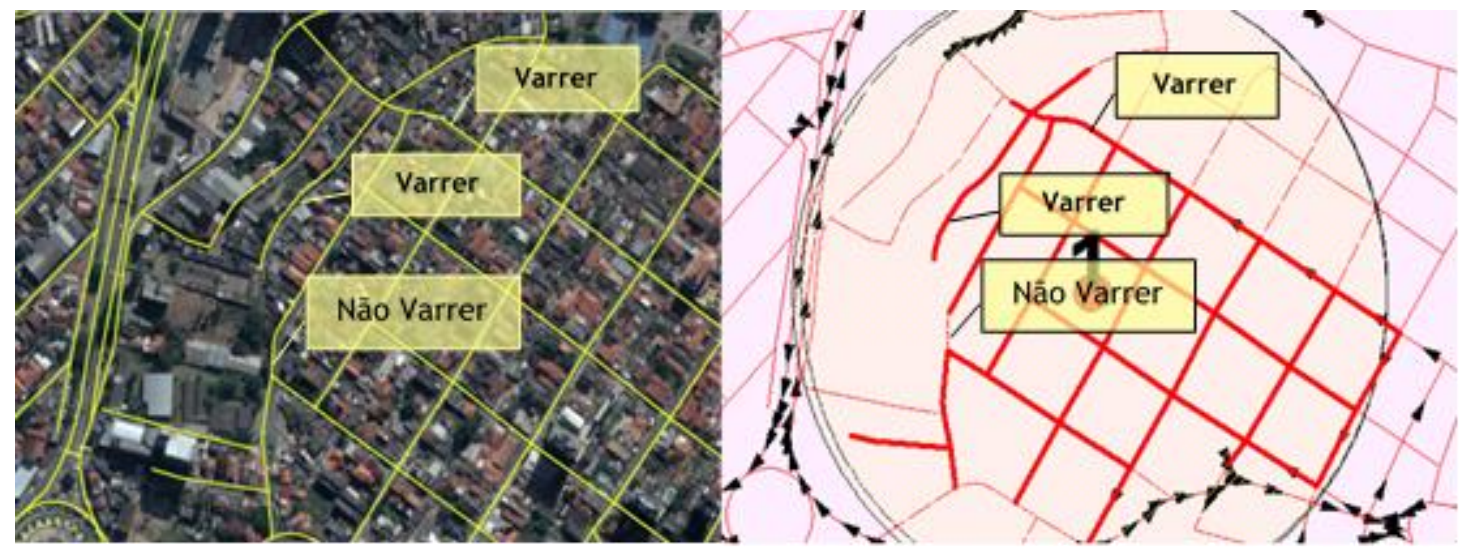

Figura 14 - Indicação de logradouros com necessidade de varrição e sem varrição.

Neste estudo, considerou-se a formação de setores de serviço de varrição, onde cada setor terá uma capacidade limitada por um perímetro máximo de varrição que não permita exceder meio turno de trabalho de cada equipe a ele atribuída. Deste modo o problema se transforma em um problema de setorização com roteirização aberto, já que em um setor agora mais de uma equipe de garis está trabalhando e nenhuma equipe poderá ter sua carga de trabalho superada sendo ainda necessário conhecer o percurso de varrição de cada equipe.
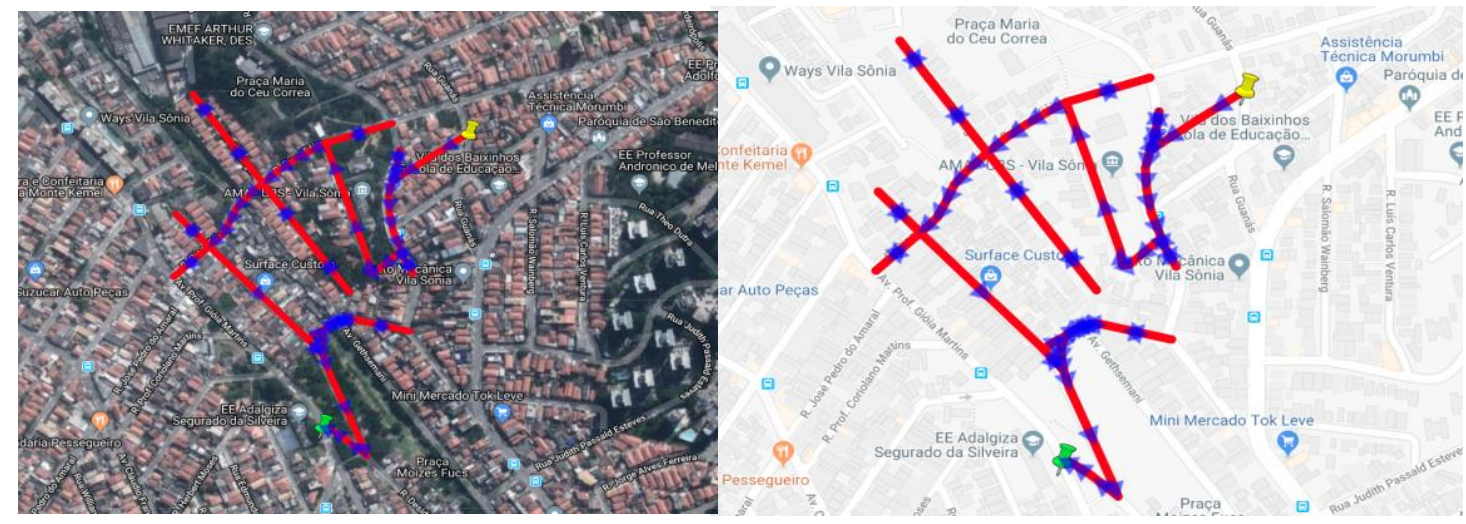

Figura 15 - Visão de um circuito de varrição definido a partir de uma solução de setorização com roteirização de varrição saindo de um ponto de apoio.

Como resultado do processo de planejamento da varrição manual a tabela 3 pode ser tomada como referência, para a análise de contexto. Foram feitos os planos de varrição manual por completo de 31 das 32 subprefeituras da cidade, ficando a subprefeitura SE (Sé), por possuir mais de 60 diferentes frequências de coleta. Os resultados foram muito animadores comparando-se aos números de Maio/2018.

Entre as soluções observou-se:

O cálculo de perímetro por eixo de varrição das subprefeituras está muito próximo na maioria dos casos um pouco maior, aos perímetros calculados e entregues pelo consórcio que atendia a zona Noroeste da cidade de SP em 2017, conforme Tabela 3. Vê-se que o número de setores apresenta 10 unidades a menos em Butantã (BT), com economia de 7,63\%, e de 14 setores a menos em Vila Maria-Vila Guilherme (VG), com economia de 20,59\%. Nota-se também uma informação discrepante na subprefeitura Santana (ST) em relação ao que se obteve no trabalho $(50,66 \%$ de diferença). Tal diferença elevada nos 
números de equipes de varrição da PMSP deve-se muito provavelmente a algum desacerto natural nas planilhas da licitação divulgadas pela AMLURB-PMSP, Tabela 3.

A tabela 3 apresenta as diferenças anotadas na otimização do número de setores, no perímetro de varrição por eixo de logradouro a ser varrido, e a medida diária de varrição. Cada setor é coberto por uma equipe de 2 varredores com um lutocar.

Tabela 3: Ganhos e perdas anotadas nos setores e diferenças de km/dia medidas.

\begin{tabular}{|c|r|r|r|r|r|r|r|}
\hline \multirow{2}{*}{ Subprefeitura } & \multicolumn{4}{|c|}{ Setores } & \multicolumn{2}{c|}{$\begin{array}{c}\text { Perímetro de Varrição } \\
(\mathrm{km})\end{array}$} & \multicolumn{2}{c|}{ km/dia Manual } \\
\cline { 2 - 9 } & Licitação & Nosso & \multicolumn{1}{|c|}{ Gap\% } & \multicolumn{1}{c|}{ Licitação } & \multicolumn{1}{c|}{ Nosso } & Licitação & \multicolumn{1}{c|}{ Nosso } \\
\hline BT & 131 & 121 & 7,63 & 763,14 & 760,29 & 275,13 & 197,72 \\
\hline CV & 82 & 60 & 26,83 & 406,52 & 407,10 & 199,392 & 156,57 \\
\hline PR & 36 & 29 & 19,44 & 165,62 & 166,82 & 61,37 & 39,62 \\
\hline ST & 152 & 75 & 50,66 & 493,95 & 321,10 & 242,765 & 148,11 \\
\hline VG & 68 & 54 & 20,59 & 395,24 & 364,24 & 395,744 & 87,75 \\
\hline
\end{tabular}

\section{CONCLUSÃO}

O framework computacional POGLI desenvolvido pela Graphvs Ltda. [11] e aqui introduzido é um ERP com integração através de webservice e apresenta um nível substancial de complexidade, haja vista o número de sistemas computacionais que o compõe. A versão para a coleta de lixo é ainda mais desafiadora, uma vez que se constitui de softwares ainda não evidentes no mercado.

Os circuitos gerados e executados no período de 23 e 25/04/18 em Campo Grande/MS proporcionaram uma redução superior a $28 \%$ na distância total percorrida pelos veículos e bem próxima da planejada inicialmente pelo SisRot ${ }^{\odot}$ LIX, de 29,3\% (Figura 6 Cenário 2). Quanto ao custo de horas de trabalho dos coletores, a discreta economia, na média de 5\%, não deixa de ser importante, pois foi possível realizar o mesmo trabalho, praticamente com o mesmo custo em homens-hora, mas percorrendo uma distância 28,5\% menor, aumentando a produtividade na mesma proporção. As economias em jornada de trabalho do motorista, superiores a $20 \%$, foram consideráveis, principalmente devido à redução de um motorista da operação analisada.

As economias em Franca/SP e Armação de Búzios/RJ foram semelhantes entre si, levando a crer que em situações com semelhança de condições geográfica e posicionamento do aterro e garagem em relação aos setores de coleta há influência na economia global a ser obtida.

As economias na varrição manual, obtidas em São Paulo, foram consideráveis, o que pode reduzir em milhões de reais o custo operacional deste serviço para a cidade, como foi aqui preconizado.

Diante destes resultados, mostrou-se a eficiência do POGLI SisRot ${ }^{\circledR}$ LIX (SAD), seus algoritmos e a equipe que o conduziu na redução dos custos operacionais, e na determinação da solução mais econômica possível para a criação dos Planos de Coleta Domiciliar e de Varrição Manual, com a otimização de setores e os respectivos roteiros de coleta e varrição. 


\section{REFERÊNCIAS BIBLIOGRÁFICAS}

[1] Mourão, M.C., Nunes, A.C., Prins, C. "Heuristic methods for the sectoring arc routing problem". Eur. J. Oper. Res. 196 (7), 856-868. 2009.

[2] Golden, B., Wong, L. (1988) “The capacitated arc routing problem", Computers and Op. Res., Vol. (), pp. .

[3] Negreiros, M., A. Palhano, A., P. Batista, and N. Maculan, "The heterogeneous sector routing problem," Submmited to Computers \& Operations Research 27pgs (2018).

[4] Corberán, A., Martí, R., A. Romero, "Heuristics for the Mixed Rural Postman Problem", Computers \& Operations Research 27, 183-203, 2000.

[5] Batista, P., Negreiros, M., Muritiba, A., Palhano, A. "New framework of metaheuristics for the Capacitated Centred Clustering Problem", Annals of MIC, 2015

[6] Negreiros, M. GTSP Based Procedures for the Mixed Rural Postman Problem, Submmited to Eur. J. Oper. Res. (2019), 27pgs.

[7] Usberti, F.; França, P.M.; França, A.M. "The open capacitated arc routing problem”, Computers \& Operations Research, Vol. 38(11), November 2011, Pages 1543-1555

[9] TURBAN, Efraim (2010). Tecnologia da Informação para Gestão: Em Busca de um Melhor Desempenho Estratégico pila grande e Operacional $7^{\mathrm{a}}$ ed. Porto Alegre: Bookman. p. 318-361

[8] Graphvs; \& Barufi (2018) "Modelos e Planos de Otimização para a Integração do Sistema Logístico de RSU da Cidade de São Paulo", PMISP-2018, São Paulo Parcerias/PMSP.

[10] Negreiros, M., Palhano, A., Rodrigues, J.A., Chaves, B., Albuquerque, I., Souza, L.P.B. "Integrated DSS Tools for Routing, Tracking and Drivers Assistance in Wholesale - SisRot ${ }^{\circledR}$, Cherry/Zeus-Track ${ }^{\circledR}$ ", Preceedings of the MCLP, 2013

[11] Graphvs (2019) www.graphvs.com.br (Acesso em 5/04/2019) 